\title{
In-vitro reactions of lymphocytes in rheumatoid arthritis and other rheumatic diseases
}

\author{
K. FROEBEL, R. D. STURROCK, P. REYNOLDS, A. GRENNAN, \\ A. ROXBURGH, AND R. N. M. MACSWEEN
}

From the Department of Pathology, Western Infirmary, Glasgow, and the Centre for Rheumatic Diseases Baird Street, Glasgow

SUMMARY Various lymphocyte functions and the percentages of different subpopulations have been measured in groups of patients with seropositive rheumatoid arthritis, seronegative ankylosing spondylitis, and psoriatic arthritis, Sjögren's syndrome, sicca complex, and in normal controls. Several abnormal results were found-in the responses to mitogens, in the antibody-dependent cytotoxic test, and in the percentages of EA rosettes (antibody sensitised chick red cells test) and surface immunoglobulin-bearing cells. In the light of these findings cytotoxicity and lymphocyte subpopulations were measured in further groups of rheumatoid arthritis patients in whom the disease was at different stages. The results showed that the changes in cytotoxic potential occurred in patients with active arthritis. Correlation tests showed significant positive associations between the percentage of SE rosette-forming cells (sheep red cells test) and the mitogenic responses to phytohaemagglutinin and concanavalin $\mathrm{A}$, and between the percentage of EA rosette-forming cells and the levels of antibody-dependent cytotoxicity. The results are discussed in the light of our understanding of cellular subpopulations in the immune system.

The interest in establishing and interpreting lymphocyte function in the rheumatic diseases has continued since lymphocytes were shown to be the major cell type involved in immune reactions and since they have been shown to be directly involved in the production and maintenance of inflammatory synovitis in rheumatoid arthritis (RA) (Pearson et al., 1975). Autoimmune diseases such as RA could result from an abnormality at 1 or more of several stages in an immune response or from a breakdown in the control of the immune system.

As well as the cellular and humoral aspects of the immune system being disturbed it is conceivable in autoimmune disease that the $\mathrm{K}$ cell, which is cytotoxic towards antibody-sensitised target cells, is involved in tissue damage. This cytotoxicity would be directed against any cell which carries the antigen against which autoantibody is directed.

Several investigations into the in-vitro reactivity of lymphocytes from patients with rheumatic diseases have been carried out, giving differing results: in mitogen-induced transformation (e.g., Lance and Knight, 1974; Lockshin et al., 1975; Rawson and

Accepted for publication 5 January 1979

Correspondence to Professor R. N. M. MacSween, Pathology

Department, Western Infirmary, Glasgow G11 6NT.
Huang, 1976), and in antibody-dependent cytotoxicity (ADC) (e.g., Scheinberg and Cathcart, 1976; Isturiz et al., 1976), although membrane marker studies of lymphocyte subpopulations have tended to show that the percentages in RA patients are normal (e.g., Sheldon et al., 1974; Brenner et al., 1975; Lockshin et al., 1975). Some of the differences in results probably arise from the differences in laboratory techniques and in the methods of analysing data obtained.

One of the main technical problems leading to variability in results is the apparently large number of different functional subpopulations of lymphocytes which cannot easily be isolated for in-vitro tests. In the present study, therefore, in which peripheral blood lymphocytes were examined from several aspects, the results were analysed by 2 approaches. Firstly, the mean results for each test obtained in the various groups were compared. Secondly, correlations were sought between pairs of tests in an attempt to find relationships between different tests and also to see if there was any consistent abnormality in the lymphocytes in any of the diseases studied. The data also made possible an evaluation of the use of such tests in the study of lymphocytes in disease. 


\section{Patients}

Specimens were obtained from the following groups at the Centre for Rheumatic Diseases in Glasgow: (a) normal controls, comprising healthy staff members; (b) definite RA (Ropes et al., 1959); (c) ankylosing spondylitis (Bennett and Burch, 1968); (d) psoriatic arthritis (Moll and Wright, 1973); (e) Sjögren's syndrome with associated RA (Block et al., 1965); $(f)$ sicca complex without associated RA (Whaley et al., 1973).

In the further study of RA patients, the groups were made up as follows: $(w)$ normal controls; $(x)$ acutely presenting RA with disease duration of less than 1 year; (y) chronic RA in remission: (i) on chemotherapy, (ii) after withholding chemotherapy for 48 hours; ( $z$ ) chronic RA with an exacerbation of the disease as judged by the examining physician, and confirmed by increased pain, morning stiffness, and joint tenderness.

No patient was tested who had received any form of therapy known to have or suspected of having an effect on immune responsiveness. This includes radiotherapy, recent surgery, or blood transfusions (Riddle and Berenbaum, 1967; Park et al., 1971), steroids, immunosuppressive drugs, gold, D-penicillamine, or levamisole (Clements, 1973; Strong et al., 1973; Hurd and Guilano, 1975; Panush and Anthony, 1976). The patients tested were either on no treatment or were receiving aspirin or related drugs, which have previously been shown not to affect lymphocyte subpopulations or mitogen responses (Froebel, unpublished results). The effect of drug removal on cytotoxicity was tested in a subgroup of RA patients.

Age- and sex-matched controls were tested on each day with the patients in order to minimise the effect of day-to-day. experimental variation.

The numbers and various details of the patient and control groups are given in Tables 1 and 2.

Table 1 Details of patients and control groups

\begin{tabular}{llll}
\hline Group & No. & $\begin{array}{l}\text { Mean age } \\
\text { (range) in } \\
\text { years }\end{array}$ & $\begin{array}{l}\text { Peripheral } \\
\text { blood } \\
\text { lymphocyte } \\
\text { count* }\end{array}$ \\
\hline & & & \\
\hline 1. Various rheumatoid diseases & & & \\
(a) Matched normal controls & 52 & $44(20-68)$ & $2500 \pm 300$ \\
(b) RA & 18 & $56(46-74)$ & $2300 \pm 400$ \\
(c) Ankylosing spondylitis & 14 & $32(17-62)$ & $2600 \pm 300$ \\
(d) Psoriatic arthritis & 14 & $46(19-63)$ & $2700 \pm 600$ \\
(e) Sjögren's syndrome & 12 & $59(40-75)$ & NT** \\
(f) Sicca complex & 10 & $62(38-74)$ & NT \\
II. Subgroups of RA & & & \\
(w) Matched normal controls & 34 & $42(24-62)$ & NT \\
(x) Early RA & 11 & $46(18-73)$ & NT \\
(y) RA in remission & 10 & $60(40-74)$ & NT \\
(z) RA in exacerbation & 10 & $56(46-69)$ & NT \\
\hline
\end{tabular}

*The number of lymphocytes per $\mathrm{mm}^{3}$ of peripheral blood ( \pm SEM). $* * N T=$ not tested.
Table 2 ESR and serum immunoglobulin levels in subgroups of RA. ESR is measured in $\mathrm{mm}$ per hour; $\operatorname{Ig} G, \operatorname{Ig} A$, and IgM levels are in $g$ per $l$

\begin{tabular}{lrrr}
\hline Group & Early $R A$ & $R A$ in remission & $\begin{array}{l}R A \text { in } \\
\text { exacerbation }\end{array}$ \\
\hline ESR & $43 \cdot 7 \pm 12 \cdot 8$ & $55 \cdot 9 \pm 8 \cdot 8$ & $66 \cdot 6 \pm 8 \cdot 5$ \\
\hline IgG & $13 \cdot 0 \pm 1 \cdot 2$ & $12 \cdot 6 \pm 1 \cdot 1$ & $16 \cdot 6 \pm 2 \cdot 5$ \\
IgA & $3 \cdot 7 \pm 0.4$ & $4 \cdot 6 \pm 0.8$ & $3 \cdot 8 \pm 0.9$ \\
IgM & $1 \cdot 5 \pm 0.2$ & $2 \cdot 2 \pm 0.5$ & $1 \cdot 5 \pm 0.2$ \\
\hline
\end{tabular}

\section{Methods}

SEPARATION OF LYMPHOCYTES

$40 \mathrm{mi}$ of venous blood from each patient and control were collected into preservative-free heparinised plastic tubes. The lymphocytes were separated by the method of Bøyum (1968) using a Ficollmetriozate gradient (specific gravity $1 \cdot 077$ ). The cells were washed 3 times in HEPES-buffered Eagle's medium, counted, and distributed for use in the various tests.

MITOGEN-INDUCED TRANSFORMATION

Lympgocytes were resuspended in bicarbonate buffered Eagle's medium containing $20 \%$ poole human AB plasma at a concentration of $1 \times 10^{\mathrm{g}}$. per ml, for phytohaemagglutinin (PHA) and con? canavalin A (con A) stimulated cultures, and at $2 \times 10^{6}$ per $\mathrm{ml}$ for pokeweed mitogen (PWM) stimulated cultures.

Reconstituted PHA (PHA-p, Wellcome) and con A (Miles Yeda) were diluted with sterile distilled water to give stock solutions containing 10 , 100 , and $1000 \mu \mathrm{g}$ per ml. PWM (Gibco) was reconstituted with $10 \mathrm{ml}$ of sterile distilled water, and stock solutions were made containing $1 \%, 10 \%$, and $100 \%$ of the original standard solutions.

Cultures were set up in triplicate in tissue-culture grade, flat-bottomed microplates (Flow Laboratories). To $0.2 \mathrm{ml}$ of lympgocyte suspension mitogen was added to give final concentrations of PHA from 0.2 to $50 \mu \mathrm{g}$ per $\mathrm{ml}$; of con A from 0.5 to $30 \mu \mathrm{g}$ per $\mathrm{ml}$, and of PWM from $0.01 \%$ to $1 \%$ of the standard solution. The microplates were incubated in a moist atmosphere of $5 \% \mathrm{CO}_{2}$ in air at $37^{\circ} \mathrm{C}$ for 3 days. Cell proliferation was measured by uptake of ${ }^{14} \mathrm{C}$-thymidine during the last 18 hours of culture. The cells were transferred on to glass fibre discs and washed with saline followed by $5 \%$ trichloracetic acid and methanol. When dry the discs were put into $10 \mathrm{ml}$ of scintillation fluid $(4 \mathrm{~g}$ per 1 'Scintimix' in toluene) and ${ }^{14} \mathrm{C}$-thymidine uptake was measured on a Packard Tricarb liquid scintillation counter. 
The arithmetic means of the results from triplicate cultures were converted from counts per minute (c.p.m.) to disintegrations per minute (d.p.m.) by counting a ${ }^{14} \mathrm{C}$ standard of known activity.

\section{ANTIBODY-DEPENDENT CYTOTOXICITY}

Cytotoxicity was measured by the method of Campbell et al. (1973). Briefly, lymphocytes, at 3 concentrations, $1 \times 10^{5}, 3 \times 10^{5}$, and $1 \times 10^{6} \mathrm{per}$ $\mathrm{ml}$, were mixed with a constant number $\left(1 \times 10^{4}\right)$ of ${ }^{51} \mathrm{Cr}$-labelled Chang cells in medium containing anti-Chang cell antiserum at a dilution of $1 \times 10^{4}$. Cytotoxicity was measured after 20 hours by centrifuging the culture tubes, removing half of the supernatant into an identical tube, and counting both tubes for $\gamma$ radiation.

The percentage of ${ }^{51} \mathrm{Cr}$ released $(\mathrm{R})$ was calculated from the formula:

$$
\mathrm{R}=\frac{2 \mathrm{Y}}{\mathrm{X}+\mathrm{Y}} \times 100
$$

where $\mathrm{X}$ and $\mathrm{Y}$ were the $\gamma$ counts in the residue and the supernatant tubes respectively. Cytotoxicity, expressed as the percentage of target cells lysis (L), was then calculated from the formula:

$$
\mathbf{L}=\frac{\mathbf{R}_{\text {test }} \text { (or } \mathbf{R}_{\text {spon) }} \mathbf{R}_{\text {min }}}{\mathbf{R}_{\max }-\mathbf{R}_{\min }} \times 100
$$

where ${ }^{R_{\text {test }}}$ and ${ }^{\mathbf{R}_{\text {spon }}}$ are the percentages of ${ }^{51} \mathrm{Cr}$ released in the presence and absence of anti-Chang antiserum respectively, ${ }^{R}$ min is the background release of ${ }^{51} \mathrm{Cr}$ by Chang cells in medium alone, and ${ }^{R_{m}}$ max is the maximal amount of ${ }^{51} \mathrm{Cr}$ release, determined by lysing $0 \cdot 1 \mathrm{ml}$ of concentrated Chang cell suspension with $2 \mathrm{ml}$ of distilled water.

\section{ROSETTE TESTS}

Rosette tests using antibody sensitised chick red cells (EA), sheep red cells (SE), or neuraminidase treated sheep red cells (SNE) were carried out by the methods described by Sandilands et al. (1976). Briefly, lymphocytes were mixed with EA, SE, or $\mathrm{SNE}$ and pelleted by centrifugation. The EA rosettes were resuspended and fixed for $20 \mathrm{~min}$ in $1.5 \%$ glutaraldehyde. The SE and SNE rosette tubes were kept at $4^{\circ} \mathrm{C}$ overnight before fixing. The cells were then stained with $0.5 \%$ trypan blue, and from each tube 1 drop was placed on each of 2 microscope slides and examined under petroleum jelly sealed coverslips. At least 200 lymphocytes on each slide were counted, and the blinding of 2 or more EA or 3 or more SE or SNE was regarded as rosette formation. Each test was performed in duplicate, so that at least 800 lymphocytes per test were examined to calculate the percentage of rosette forming cells.
SURFACE IMMUNOGLOBULIN

Two million lymphocytes were resuspended in $0 \cdot 1$ $\mathrm{ml}$ of phosphate buffered saline (PBS) in $1.5 \mathrm{ml}$ capacity centrifuge tubes. To these, $0.1 \mathrm{ml}$ of a $1: 20$ dilution of fluorescein conjugated swine antihuman immunoglobulin (Nordic Laboratories) was added, and the tubes were incubated in the dark for $\mathbf{4 5}$ minutes at room temperature. The cells were then washed twice and resuspended in 2-3 drops of a 1:1 PBS-glycerol mixture. One drop was put on to a microscope slide and the cells were examined under a petroleum jelly sealed coverslip by incident blue light to identify the fluorescing lymphocytes and by transmitted white light and a dark ground condenser to identify the total cell population. Phagocytic monocytes were distinguished from lymphocytes by prior incubation of the cells with latex particles (Singh et al., 1974). Two separate counts of at least 100 cells were made on each side to determine the percentage of lymphocytes bearing surface immunoglobulin (SIg).

\section{ANALYSIS OF RESULTS}

The results were analysed on IBM 360/65 and 370/ 168 computers by a system of prewritten programsthe Statistical Package for the Social Sciences' (SPSS) (Nie et al., 1975).

Initially the distribution of the results of each test for each patient group was analysed. These approached a normal distribution except for the response of $0.2 \mu \mathrm{g} / \mathrm{ml}$ phytohaemagglutinin (PHA) in the sicca complex patients. With this 1 exception, therefore, the mean results for each patient group could be compared with the controls by means of Student's $t$ test. The Mann-Whitney test was used to compare the $0 \cdot 2 \mu \mathrm{g} / \mathrm{ml}$ PHA results for the sicca complex patients.

In the follow-up study of RA subgroups the possible error introduced by doing a large number of Student's $t$ tests was reduced by comparing the means of the results by analysis of variance, and in cases where the $F$ value was statistically significant the specific difference were located by the methods of angular transformation and multiple comparisons (Armitage, 1971).

Subsequently the data were analysed to look for associations between functional tests and lymphocyte subpopulations, that is, between individual lymphocyte subpopulations and (1) mitogen responsiveness and (2) ADC. Correlations were also sought between the in-vitro results, age, and serological indices. Because of the large number of correlation tests carried out, significant correlation coefficients between tests of lymphocyte function and a particular lymphocyte subpopulation were considered relevant only if they were consistent for 
several of the concentrations at which the functional test was carried out.

\section{Results}

The results of the various tests are shown graphically-the numerical data are available on request.

\section{MITOGEN-INDUCED TRANSFORMATION}

The results of the PHA, con A, and PWM stimulated cultures are shown in Fig. 1. The seropositive RA group showed slightly reduced responses, particularly to low concentrations of PHA. The differences were just significant at the $0.2 \mu \mathrm{g}$ per $\mathrm{ml}$ and $0.5 \mu \mathrm{g}$ per $\mathrm{ml}$ doses of PHA $(\mathrm{P}=0.047$ and 0.048 respectively).

The Sjögren's syndrome group had a significantly reduced response to $0.5 \mu \mathrm{g}$ per ml PHA $(\mathrm{P}=0.005)$ and to $0.1 \% \mathrm{PWM}(\mathrm{P}=0.029)$. The sicca complex group had a reduced response to PHA which was significant at the $0.2 \mu \mathrm{g}$ per $\mathrm{ml}(\mathrm{P}<0.02)$ and at the $0.5 \mu \mathrm{g}$ per $\mathrm{ml}$ concentrations $(\mathrm{P}<0.001)$.

In the patients with seronegative arthritis there were no significant differences between the means of the ankylosing spondylitis and control groups with any of the 3 mitogens. The psoriatic arthritis group showed a reduced response to PHA compared with the controls; this was significant at the $1.0 \mu \mathrm{g}$ per ml $\mathrm{w}$.

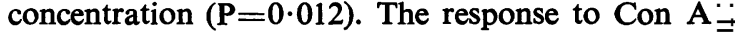
of the psoriatic arthritis was significantly reduced os at the 2 highest concentrations tested, $(P=0.011$ ato $10 \mu \mathrm{g}$ per $\mathrm{ml}$ and $\mathrm{P}=0.004$ at $30 \mu \mathrm{g}$ per $\mathrm{ml}$ con $\mathrm{A}$ ).

\section{ANTIBODY-DEPENDENT CYTOTOXICITY}

The results of the first study are shown in Fig. 2 as the spontaneous and specific cytotoxicity using $1 \times 10^{4}$ Chang cells at the 3 lymphocyte concentrations tested. The seropositive RA patients showed $\vec{\omega}$ a very significant reduction in specific cytotoxicity, the significance levels being $\mathrm{P}=0 \cdot 019,0 \cdot 010$, and 0.001 for the $1 \times 10^{5}, 3 \times 10^{5}$, and $1 \times 10^{6}$ per ml lymphocyte concentrations respectively.

In the seronegative patients the ankylosing spondylitis group showed a significantly reduced level of ${ }_{G}^{\mathcal{H}}$ specific cytotoxicity compared with the controlso at both the $3 \times 10^{5}$ and $1 \times 10^{6}$ per ml lymphocyte concentrations $(P=0.026$ and 0.007 respectively).

The results of the follow-up study are shown in Fig. 3. In the group of RA patients who were experi- $\frac{\mathbb{O}}{3}$ encing an exacerbation of their disease there was $a$ significant reduction in both specific and total cytotoxicity levels at the $1 \times 10^{6}$ lymphocytes per 11

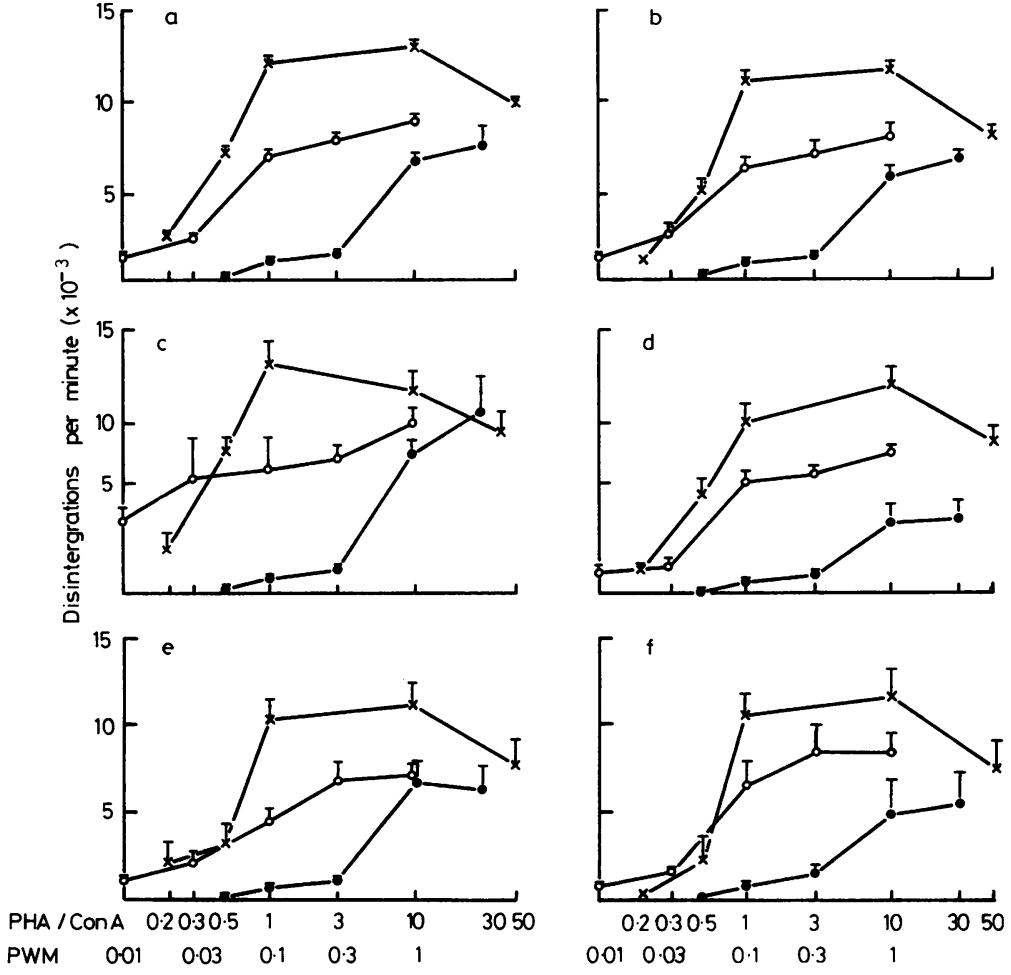

Fig. 1 Lymphocyte transformation responses to PHA (-x-), Con $A$ $(-\bullet-)$ and PWM (-O-) in; (a) normal controls (b) rhoumatoid arthritis, (c) ankylosing spondylitis, $\circ$ (d) psoriatic arthritis, (e) Sjögren's syndrome, and (f) sicca complex. Results are expressed as the mean d.p.m. + SEM. The concentrations N of $P H A$ and of con $A$ are in $\mu g$ per $\mathrm{ml}$, and of PWM as the strength of solution relative to the stock solution 

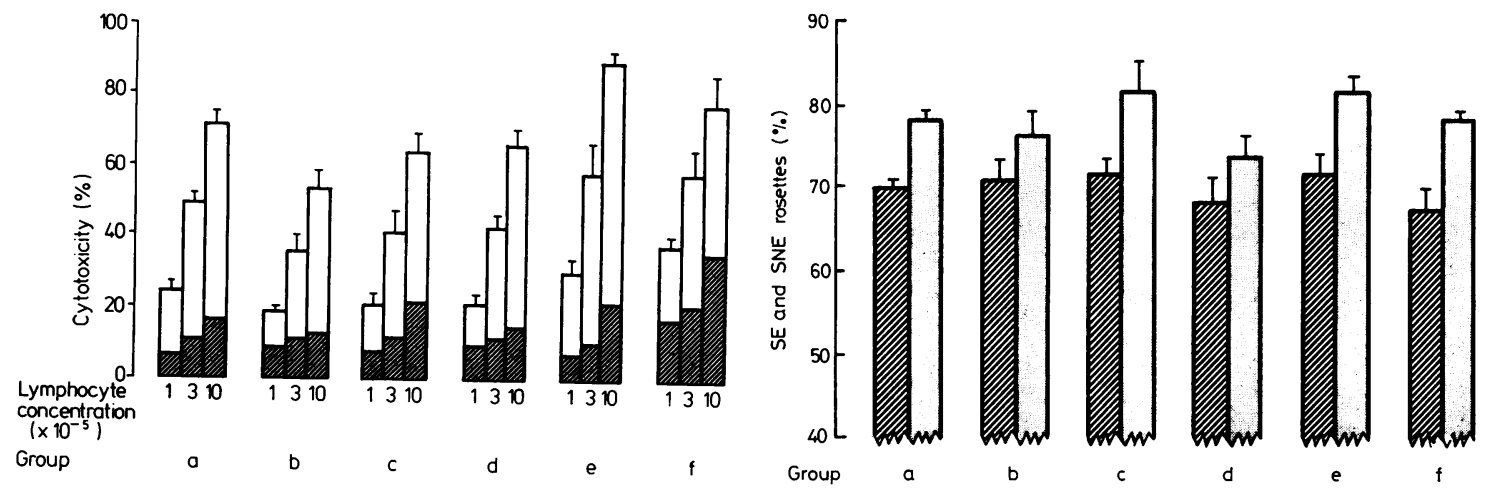

Fig. 2 Antibody-dependent cytotoxicity by different concentrations of lymphocytes against $1 \times 10^{4}$ Chang cells. The groups are as for Fig. 1. Results are expressed as the mean spontaneous (hatched shading) and specific cytotoxicity (open histograms) + the SEM of the total cytotoxicity results

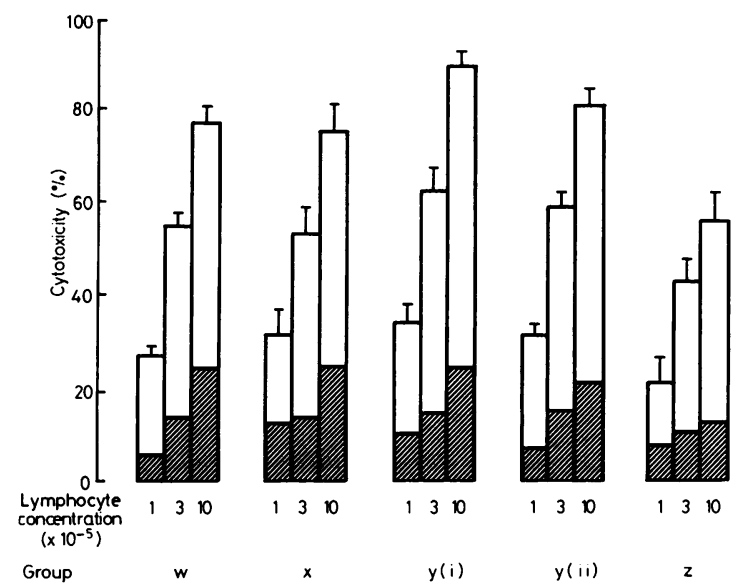

Fig. 3 Antibody-dependent cytotoxicity by different concentrations of lymphocytes against $1 \times 10^{4}$ Chang cells in; (w) normal controls, (x) early $R A,(y i) R A$ in remission on chemotherapy, (y ii) $R A$ in remission after withholding chemotherapy for 48 hours, (z) RA in exacerbation. Results are expressed as the mean spontaneous (hatched shading) and specific cytotoxicity (open histograms) + SEM of the total cytotoxicity results

concentration $(P<0 \cdot 05)$. Cytotoxicity was within the normal limits in the 'early RA' group and in the 'RA in remission group' group. Withholding antiinflammatory therapy for $\mathbf{4 8}$ hours had no ignificant effect on the cytotoxicity results.

\section{ROSETTE TESTS}

The results of the EA rosette tests are shown in Fig. 4.

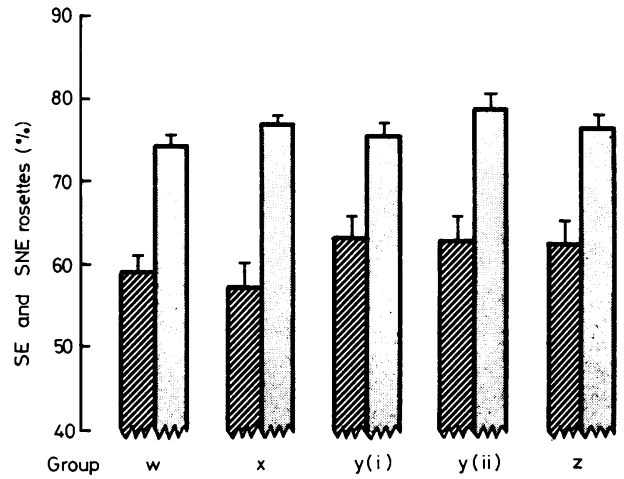

Fig. 4 The percentages (mean + SEM) of SE (hatched shading) and SNE rosettes (speckled shading). The groups are as for Figs. 1 and 3

Although in the initial study the RA patients had a lower mean percentage of EA rosette-forming lymphocytes than the controls $(14 \cdot 3 \% \pm 1 \cdot 5 \%$ (SEM) and $19.0 \% \pm 1 \cdot 2 \%$ respectively $P=0.046$ ), the follow-up study did not confirm the difference. The results of the SE and SNE rosette tests (Fig. 5) showed no significant differences between any of the groups.

\section{SURFACE IMMUNOGLOBULIN}

The results are shown in Fig. 6. In the initial study, the Sjögren's syndrome group had a significantly higher mean percentage of SIg-bearing lymphocytes than the controls $(16 \cdot 8 \% \pm 2 \cdot 8 \%$ SEM $)$ and $10 \cdot 3 \%$ $\pm 1.0 \%$ respectively, $\mathrm{P}=0.011$ ).

The sicca complex group had a mean percentage of SIg-bearing cells $(14 \cdot 3 \% \pm 1 \cdot 7 \%)$ which was intermediate between the RA and the RA plus Sjögren's syndrome results. In the subsequent study the mean percentage was significantly raised in the group of RA patients in remission $(19 \cdot 0 \pm 3 \cdot 6$ (SEM); the control mean in this study was $12 \cdot 1 \pm$ $1 \cdot 1, P<0 \cdot 05$ ). Although there was a slight increase 

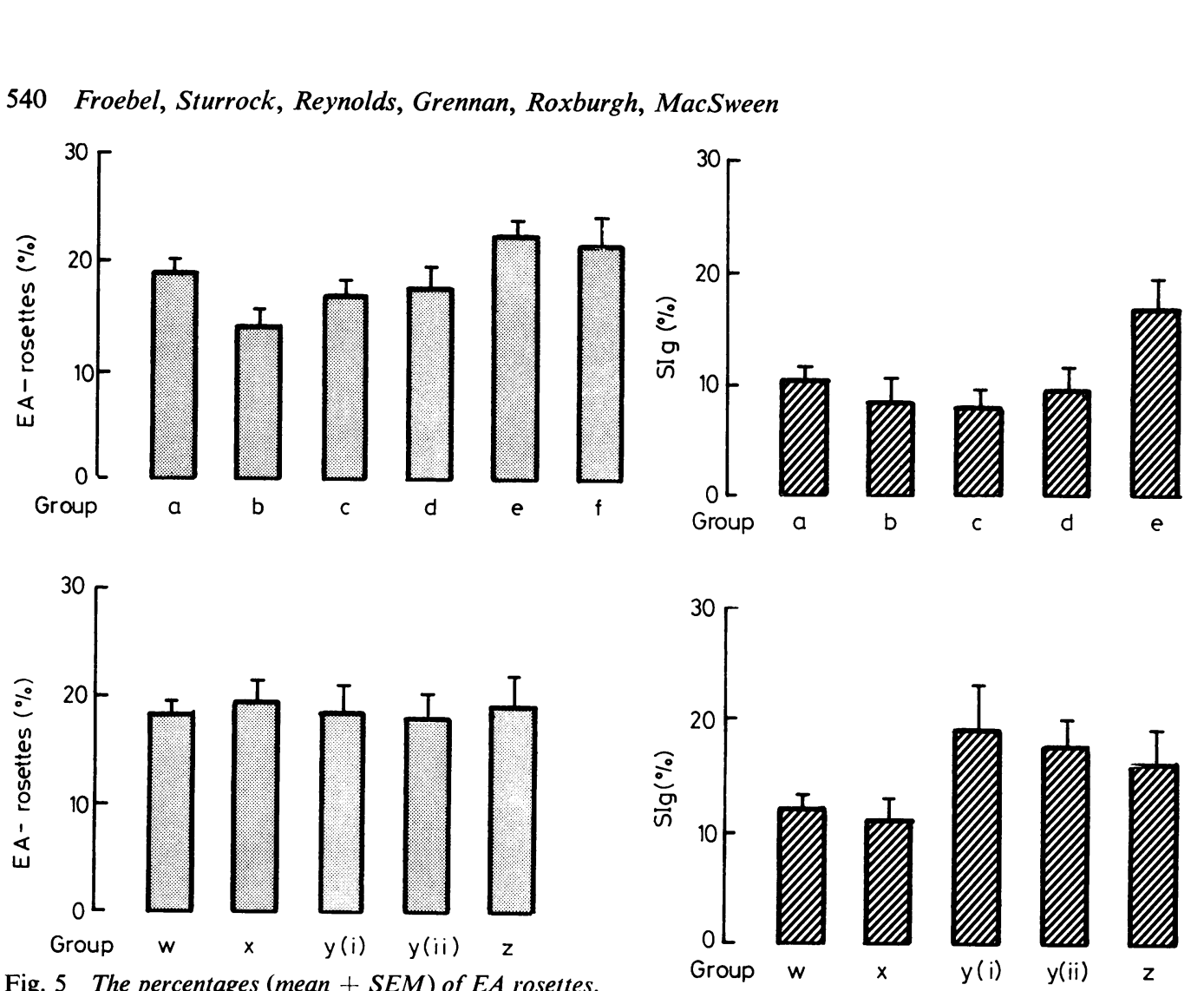

Fig. 5 The percentages (mean $+S E M)$ of EA rosettes. The groups are as for Figs. 1 and 3

in the RA patients in exacerbation $(15 \cdot 8 \pm 2 \cdot 9)$, the difference was not significant.

HAEMATOLOGY AND SEROLOGY

The mean erythrocyte sedimentation rate (ESR) values and serum immunoglobulin levels measured in the RA subgroups are given in Table 2. The ESR values increased with increasing disease severity, as expected, while the mean levels of $\mathrm{IgG}, \mathrm{IgA}$, and $\operatorname{IgM}$ were within the normal limit.

\section{CORRELATION TESTS}

The results of the correlation tests are shown in Tables 3 and 4.

In the first study only the data from the control group were used for the correlation tests. This was a precaution taken in case, in a disease group, an abnormality might occur in one test but not in another related test, for instance, if a particular function was abnormal although the lymphocyte subpopulations were normal. On examination the results were found to be similar irrespective of whether the control group data alone or the pooled data from all the groups were analysed. In the followup study, therefore, in which the numbers in each

Fig. 6 The percentages (mean $+S E M$ ) of surface immunoglobulin-bearing cells. The groups are as for Figs. 1 and 3

Table 3 Correlations between the lymphocyte responses to mitogens and (1) subpopulations and (2) age, using data from the normal controls-group (a)

\begin{tabular}{lllllll}
\hline Mitogen & \multicolumn{2}{l}{ SE rosettes } & EA rosettes & \multicolumn{2}{l}{ Age } & \\
\cline { 2 - 7 } & $P$ & $P$ & $r$ & $P$ & $r$ & $P$
\end{tabular}

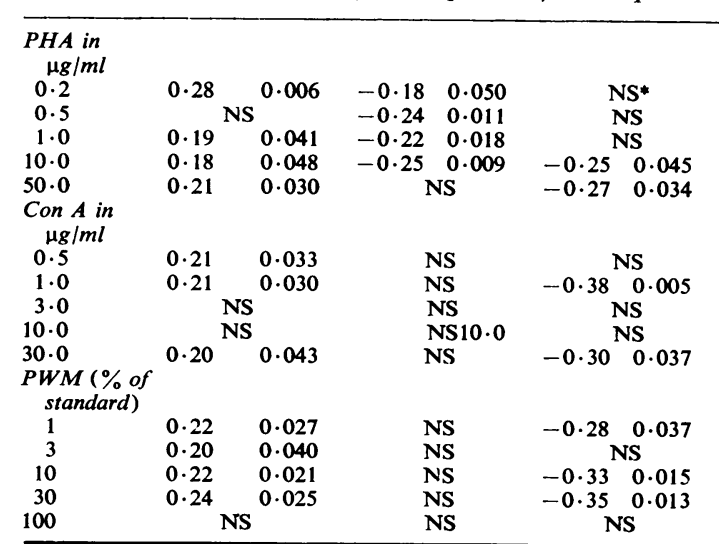

$r=$ Correlation coefficient. $\quad P=$ Significance level. $\quad * N S=$ not significant at the $5 \%$ level (Pearson's correlation test). 
Table 4 Correlation between ADC and lymphocyte subpopulations

\begin{tabular}{|c|c|c|c|c|c|c|}
\hline \multirow{2}{*}{$\begin{array}{l}\text { Lymphocyte } \\
\text { concentration } \\
\text { (per } m l)\end{array}$} & \multicolumn{2}{|l|}{$S I^{1}$} & \multicolumn{2}{|c|}{ EA rosettes ${ }^{1}$} & \multicolumn{2}{|c|}{$E A$ rosettes $^{2}$} \\
\hline & $r$ & $\boldsymbol{P}$ & $\boldsymbol{r}$ & $\boldsymbol{P}$ & $\boldsymbol{r}$ & $\boldsymbol{P}$ \\
\hline \multicolumn{7}{|l|}{$\begin{array}{l}\text { Total } \\
\text { cytotoxicity } \\
\text { results }\end{array}$} \\
\hline $\begin{array}{r}1 \times 10^{5} \\
3.3 \times 10^{5} \\
1 \times 10^{6}\end{array}$ & $\begin{array}{l}0.21 \\
0 \cdot 27 \\
0 \cdot 38\end{array}$ & $\begin{array}{l}0.030 \\
0.007 \\
0.001\end{array}$ & $\begin{array}{l}0 \cdot 37 \\
0.45 \\
0.42\end{array}$ & $\begin{array}{l}0.001 \\
0.001 \\
0.001\end{array}$ & $\begin{array}{l}0.53 \\
0.54 \\
0.57\end{array}$ & $\begin{array}{l}0.00001 \\
0.00001 \\
0.00001\end{array}$ \\
\hline $\begin{array}{l}\text { Specific } \\
\text { cytotoxicity } \\
\text { results }\end{array}$ & & & & & & \\
\hline $\begin{array}{r}1 \times 105 \\
3.3 \times 105 \\
1 \times 106\end{array}$ & $\begin{array}{l}\mathbf{N} \\
0 \cdot 26 \\
0 \cdot 32\end{array}$ & $\begin{array}{l}\text { JS* } \\
0.010 \\
0.010\end{array}$ & $\begin{array}{l}0.42 \\
0.54 \\
0.45\end{array}$ & $\begin{array}{l}0.001 \\
0.001 \\
0.001\end{array}$ & $\begin{array}{l}0.45 \\
0.47 \\
0.43\end{array}$ & $\begin{array}{l}0.00001 \\
0.001 \\
0.0001\end{array}$ \\
\hline
\end{tabular}

1 Data from 52 controls (First study). 2 Data from 65 controls and patients (follow-up study). $r=$ Correlation coefficient. $P=$ Significance level. $*$ NS $=$ Not significant at the $5 \%$ level (Pearson's correlation test).

group were small, the data were pooled for the correlation analysis.

The first study showed a slight but consistently positive association between the transformation results with each mitogen and the percentage of SE rosettes, and a corresponding negative association between the PHA results and the percentage of EA rosettes (Table 3 ). The results also revealed a slight but consistent negative correlation between age and the transformation response to all three mitogens (Table 3 ). The cytotoxicity results correlated with the percentage of EA rosettes, and to a less extent (that is with low $r$ values) with the percentage of SIgbearing cells (Table 4 ).

In the follow-up study still higher correlation coefficients, which were more highly significant, were shown between the cytotoxicity and EA rosette results (Table 4). No associations could be shown between haematological or serological indices and either the cytotoxicity or the lymphocyte subpopulation results (data not shown).

\section{Discussion}

The abnormal responses in patients in the tests of lymphocyte function reported above have nearly all tended to be in the direction of a reduced response. The problem of such in-vitro tests, however, is in knowing precisely which of the functional subpopulations of lymphocytes a particular test is measuring. Cellular ( $T$ cell mediated) immune reactions are being seen increasingly to be controlled by interactions between subpopulations of $T$ cellsprimarily as a balance between helper and suppressor T cells (Allison et al., 1971; Dutton, 1975; Mitsuoka et al., 1976). So although lymphocyte responses to PHA and con A have been widely used as an index of $\mathrm{T}$ cell function (Greaves et al., 1974; Campbell et al., 1973; MacSween et al., 1973; Mellstadt and Holm, 1973) the activities of these mitogens are now being described increasingly in terms of $\mathrm{T}$ cell subpopulations (Hubert et al., 1976; Tse and Dutton, 1977). The reduced responses by RA patients, Sjögren's syndrome and sicca complex patients to low doses of PHA, but their normal responses to con A may mean that these patients are defective in a particular subpopulation of $T$ cells or that their cells require a higher concentration of PHA to be 'switched on'. So too the abnormality in psoriatic arthritis (this group had reduced responses to high doses of both PHA and con A) may be in a T cell subpopulation, that, is, both PHA and con A responsive. Conceivably, reduced responses to non specific mitogens may be a result of an ongoing immune responses being mounted against some, as yet unknown, disease associated antigen.

The numbers of $\mathrm{T}$ cells, measured by the $\mathrm{SE}$ and SNE rosette tests, were within the normal range for all the patient groups tested. This finding supports the view that a numerically small subpopulation of $\mathbf{T}$ cells is sufficient to cause abnormal functional responses. The statistically significant but low correlation coefficient obtained between PHA and con A induced proliferation, and the percentage of SE (but not SNE) rosettes, shows that, while there is a positive relationship between these tests, factors other than merely the number of SE rosette-forming cells determine the extent of mitogen induced proliferation.

Patients with RA and to a less extent those with ankylosing spondylitis also showed diminished ADC against antibody sensitised Chang target cells. This finding was of particular interest in RA, since in patients with rheumatoid factor all the components required for an $\mathrm{ADC}$ reaction are present, and the question arises whether $K$ cells mediate damage against immunoglobulin-bearing autologous cells. Our study cannot answer this question, but the follow-up study of subgroups of RA patients has shown that $K$ cell activity is reduced, particularly in RA patients who are experiencing an exacerbation of their disease. This finding is at variance with some other studies of ADC in RA, which show either normal (Diaz-Jouanen et al., 1976; Scheinberg and Cathcart, 1976) or increased (Sany et al., 1977) activity in patients. These groups, however, used red blood cells as targets, and there is some evidence to suggest that different effector cells may be involved in killing these targets as opposed to metabolically active Chang cells (Scornik et al., 1974; Kovithavongs et al., 1975; Sanderson and Taylor, 1976). However, Isturiz et al., (1976) have reported reduced ADC against red blood cells in RA and McGill and 
Twinn (1977), also using red cells, found retrospectively that there was an inverse correlation between disease activity and $\mathrm{K}$ cell activity. The study of McGill and Twinn, together with our own, shows the need to use well-defined groups of patients for this type of investigation.

Barnett and MacLennan (1968) reported that sera from some RA patients inhibited ADC probably via the binding of immune complexes to the Fc receptors on the $\mathrm{K}$ cell. These complexes would need to bind particularly avidly to survive the 3 washes given during lymphocyte preparation, but this explanation is in keeping with the view that the $\mathrm{K}$ cell belongs to a small subpopulation of $\mathrm{Fc}$ receptor-bearing cells with particularly avid binding receptors (Revillard et al., 1975; Sany et al., 1976). Whether reduced $\mathrm{K}$ cell activity is a byproduct of an exacerbation of disease, or whether the inhibition of $\mathrm{K}$ cells by immune complexes leads to the exacerbation, is an intriguing question which still needs to be answered.

The correlation tests between the cytotoxicity results and the lymphocyte subpopulation tests confirm the relationship between cytotoxicity and the EA rosette-forming cell shown by several authors (e.g., De Bracco et al., 1976; Hersey et al., 1976; Sandilands et al., 1976). However, the EA rosette test was not a sufficiently accurate measure of $K$ cell activity to mirror the reduced cytotoxicity in the RA subgroup.

We cannot explain the increase in SIg-positive cells in the patients with Sjögren's syndrome and those with 'RA in remission'. Talal et al. (1974) obtained similar results in Sjögren's syndrome and attributed these to the binding of immune complexes to the lymphocyte membrane. Our results do not accord with this explanation, however, since immune complexes would be expected to inhibit ADC, and this was normal in these patients.

In conclusion, the results presented here show a generally reduced immunological responsiveness in RA by in-vitro tests, particularly, in patients in whom the disease is active and of long standing. The methods used, however, were unable to implicate a particular lymphocyte subpopulation. Our understanding of the immunological abnormalities in RA and other rheumatic diseases will become clearer as the functional subpopulations and their interdependence are characterised in greater detail. Future studies of immunological responses in the rheumatoid diseases will need to focus on specific effects mediated by defined subgroups or clones of reactive cells.

The statistical advice of Dr M. Titterington of the University of Glasgow Department of Statistics is gratefully acknowledged. This work was supported by grants from the Biomedical Research Committee of the Scottish Home and
Health Department (to R.N.M.McS.) and from the Arthritis and Rheumatism Council (to Professor W. W. Buchanan at the Centre for Rheumatic Diseases).

\section{References}

Allison, A. C., Denman, A. M., and Barnes, R. D. (1971). Cooperating and controlling functions of thymus-derived $\overline{\bar{N}}$ lymphocytes in relation to autoimmunity. Lancet, 2, 135140.

Armitage, P. (1971). Statistical Methods in Medical Research. هి Blackwell: Oxford.

Barnett, J. G., and MacLennan, J. C. M. (1968). Inhibitory $\vec{O}$ effect of rheumatoid sera on cell damage by lymphocytes. Annals of the Rheumatic Diseases, 31, 425 (abstract). $\vec{\omega}$

Bennett, P. H., and Burch, T. A. (1968). The epidemiological o diagnosis of ankylosing spondylitis. Population Studies of the Rheumatic Diseases, p. 305. Edited by P. H. Bennett and P. H. Wood. Excerpta Medica: Amsterdam.

W

Bloch, K. J., Buchanan, W. W., Wohl, M. J., and Bunin, ${ }^{\circ}$ J. J. (1965). Sjögren's syndrome: a clinical, pathological of and serological study of 62 cases. Medicine, 44, 187-231. W

Bøyum, A. (1968). A one-stage procedure for isolation of granulocytes and lymphocytes from human blood. Scandinavian Journal of Clinical and Laboratory Investi- gation, 21, Suppl. 97, 51-76.

Brenner, A. I., Scheinberg, M. A., and Cathcart, E. S. (1975). Surface characteristics of synovial fluid and peripheral $\Phi$ blood lymphocytes in inflammatory arthritis. Arthritis and Rheumatism, 18, 297-303.

Campbell, A. C., Hersey, P., MacLennan, I. C. M., Kay, H. E. M., and McPike, M. C. (1973). Immunosuppressioe 6 consequences of radiotherapy and chemotherapy inco patients with acute lymphoblastic leukaemia. Britit $h^{*}$ Medical Journal, 2, 385-388.

Clements, P. (1973). Immunosuppressive effects on $\overrightarrow{\mathrm{B}}-\sum_{-}$ lymphocytes in rheumatoid arthritis. Arthritis and Rheumatism, 16, 537 (abstract).

DeBracco, M. M., Isturiz, M. A., and Manni, J. A. (1976). ํํำ Cell mediated cytotoxocity: characterisation of the effector cells. Immunology, 30, 325-333.

Diaz-Jouanan, E., Bankhurst, A. D., and Williams, R. C., 윽 Jr. (1976). Antibody mediated cytotoxicity in rheumatoid arthritis and systemic lupus erythematosus. Arthritis and Rheumatism, 19, 133-141.

Dutton, R. W. (1975). Suppressor T-cells. Transplantation Reviews, 26, 39-55.

Greaves, M., Janossy, G., and Doenhoff, M. (1974). Activation of human $T$ - and B-lymphocytes by polyclona $B$ mitogens. Journal of Experimental Medicine, 140, 1-18.

Hersey, P., Edwards, A., and Edwards, J. (1976). Characteri-O sation of mononuclear effector cells in human blood Clinical and Experimental Immunology, 23, 104-113.

Hubert, C., Delespesse, G., and Govaerts, A. (1976). Conconavalin $\mathbf{A}$ activated suppressor cells in normal human peripheral blood lymphocytes. Clinical and ExperimentaE. Immunology, 26, 95-98.

Hurd, E., and Guilano, V. J. (1975). The effect of cyclophos? phamide on B- and T-lymphocytes in patients with con- N nective tissue diseases. Arthritis and Rheumatism, 18, 67-75응

Isturiz, M. A., De Bracco, M. M. DeE., Pizzi, A. M., andw Manni, J. A. (1976). Antibody dependent cell mediatedo cytotoxicity in rheumatoid arthritis: effect of rheumatoid serum fractions on normal lymphocytes. Arthritis and Rheumatism, 19, 725-730.

Kovithavongs, T., Rice, G., Thong, K. L., and Dossetor, J. B. (1975). Effector cell activity in antibody mediated celro dependent immune lysis. II. Evidence for different popū lations of effector cells for different targets. Cellulard Immunology, 18, 167-175. 
Lance, E. M., and Knight, S. C. (1974). Immunologic reactivity in rheumatoid arthritis: response to mitogens. Arthritis and Rheumatism, 17, 513-520.

Lockshin, M. D., Eisenhaur, A. C., Kohn, R., Weksler, M., Block, S., and Mushlin, S. B. (1975). Cell mediated immunity in the rheumatic diseases. II. Mitogen responses in RA, SLE and other illnesses: correlation with T- and B-lymphocytes, Arthritis and Rheumatism, 18, 245-250.

McGill, P. E., and Twinn, I. (1977). Antibody mediated cytotoxicity in rheumatoid arthritis. Annals of the Rheumatic Diseases, 36, 268-270.

MacSween, R. N. M., Galbraith, I., Thomas, M., Watkinson, G., and Ludlam, G. B. (1973). Phytohaemagglutinin (PHA) induced lymphocyte transformations and Toxoplasma gondii antibody studies in primary biliary cirrhosis. Clinical and Experimental Immunology, 15, 35-42.

Mellstedt, H., and Holm, G. (1973). In vitro studies of lymphocytes from patients with plasma cell myeloma. Clinical and Experimental Immunology, 15, 309-320.

Mitsouka, A., Babab, M., and Morikawa, S. (1976). Enhancement od delayed hypersensitivity by depletion of suppressor T-cells with cyclophosphamide in mice. Nature, 262, 77-78.

Moll, I., and Wright, V. (1973). Familial concurrence of psoriatic arthritis. Annals of the Rheumatic Diseases, 32, 181-201

Nie, N. H., Hull, C. H., Jenkins, J. G., Steinbrenner, K., and Bent, D. H. (1975). Statistical Package for the Social Sciences, 2nd edn. McGraw-Hill: New York.

Panush, R. S., and Anthony, C. R. (1976). Effects of acetylsalicyclic acid on normal peripheral blood lymphocytes. Clinical and Experimental Immunology, 23, 114-125.

Park, S. K., Brody, J. I., Wallace, H. A., and Blackmore, N. S. (1971). Immunosuppressive effects of surgery. Lancet, 1, 53-55.

Pearson, C. M., Paulus, H. E., and Machleder, H. I. (1975). The role of the lymphocyte and its products in the propagation of joint disease. Annals of the New York Academy of Sciences, 256, 150-168.

Rawson, A. J., and Huang, T. C. (1976). Lymphocyte populations in rheumatoid arthritis. Arthritis and Rheumatism, 19, 720-724.

Revillard, J. P., Samarut, C., Cordier, G., and Brochier, J. (1975). Characterisation of human lymphocytes bearing Fc-receptors with special reference to cytotoxic (K) cells. Proceedings of the International Symposium on Membrane Receptors of Lymphocytes, p. 171. Edited by M. Seligmann, J. I. Preud'homme, and F. M. Kourilsky, North Holland Publishing Co.: Amsterdam.
Riddle, P. R., and Berenbaum, M. C. (1967). Postoperative depression of the lymphocyte response to phytohaemagglutinin. Lancet, 2, 367.

Ropes, M. W., Bennett, P. A., and Cobb, S. (1959). Diagnostic criteria for rheumatoid arthritis. Annals of the Rheumatic Diseases, 18, 49-53.

Sanderson, C. J., and Taylor, G. A. (1976). Antibody dependent cell mediated cytotoxicity in the rat: the role of macrophages. Immunology, 30, 117-121.

Sandilands, G., Gray, K., Cooney, A., Froebel, K., and Anderson, J. R. (1976). Human lymphocyte subpopulations and K-cells. International Archives of Allergy and Applied Immunology, 50, 416-426.

Sany, J., Clot, J., Frietas, M., Charmasson, E., and Serre, H. (1976). Antibody dependent cell cytotoxicity (ADCC) of rheumatoid arthritis blood lymphocytes. Revue du Rheumatism et des Maladies Ostéo-articulaires, 43, 333388.

Scheinberg, M. A., and Cathcart, E. S. (1976). Antibody dependent direct cytotoxicity of human lymphocytes. II. Studies on peripheral blood lymphocytes, synovial fluid cells and sera from patients with rheumatoid arthritis. Clinical and Experimental Immunology, 24, 323-327.

Scornik, J. C., Cosenza, H. Lee. W., Köhler, H., and Rowley, D. A. (1974). Antibody dependent cell mediated cytotoxicity by 'normal' IgG Journal of Immunology, 113, 1510-1518.

Sheldon, P. J., Papamichael, M., and Holborow, E. J. (1974). Studies on synovial fluid lymphocytes in rheumatoid arthritis. Annals of the Rheumatic Diseases, 33, 509-514.

Singh, J., Elson, C. J., and Taylor, R. B. (1974). Enrichment in B-cells after separation of lymphocytes from peripheral blood. Journal of Immunological Methods, 5, 111-119.

Strong, J. S., Bartholomew, B. A., and Smyth, C. J. (1973). Immunoresponsiveness of patients with $\mathrm{RA}$ receiving cyclophosphamide or gold salts. Annals of the Rheumatic Diseases, 32, 233-237.

Talal, N., Sylvester, R. A., Daniels, T. E., Greenspan, J. S., and Williams, R. C., Jr. (1974). T- and B-lymphocytes in peripheral blood and tissue lesions in Sjögren's syndrome. Journal of Clinical Investigation, 53, 180-189.

Tse, H. Y., and Dutton, R. W. (1977). Separation of helper and suppressor T-lymphocytes. Journal of Experimental Medicine, 146, 747-758.

Whaley, K., Williamson, J., Chisholm, D. M., Webb, J., Mason, D. K., and Buchanan, W. W. (1973). Sjögren's syndrome: I. Sicca components. Quarterly Journal of Medicine, 42, 279-304. 